\title{
The Influence of Lubricant Degradation on Measured Piston Ring Film Thickness in a Fired Gasoline Reciprocating Engine
}

\author{
Rai Singh Notay ${ }^{1)}$, Martin Priest ${ }^{2)}$ and Malcolm F Fox ${ }^{2)}$ \\ 1) Rai.Notay@Gmail.com \\ 2) Faculty of Engineering and Informatics, University of Bradford, Bradford, BD7 1DP, UK
}

\begin{abstract}
A laser induced fluorescence system has been developed to visualise the oil film thickness between the piston ring and cylinder wall of a fired gasoline engine via a small optical window mounted in the cylinder wall. A fluorescent dye was added to the lubricant in the sump to allow the lubricant to fluoresce when absorbing laser radiation. The concentration of the dye did not disturb the lubricant chemistry or its performance. Degraded engine oil samples were used to investigate the influence of lubricant quality on ring pack lubricant film thickness measurements. The results show significant differences in the lubricant film thickness profiles for the ring pack when the lubricant degrades which will affect ring pack friction and ultimately fuel economy.
\end{abstract}

\section{Introduction}

With the drive towards better energy resource utilisation and an improved environment, current automotive engine tribology research is geared towards reduced pollutant emissions and improved efficiency. A large proportion of the internal friction of an engine is due to the piston assembly, comprising the piston ring pack and the piston skirt, and the lubricant in the ring pack also plays a vital role in exhaust emissions control $[1,2]$. Demands on the engine lubricant to help improve engine efficiency are becoming more intense and recent engine technology, such as engine downsizing and stop start functions, are increasing the stress on modern engine lubricants. Consequently, there is a growing need to investigate the influence of lubricant degradation on the tribological behaviour of the engine. The trend to use less viscous lubricants to reduce engine frictional power loss, whilst still maintaining engine wear protection over long oil drain intervals, is further exacerbating this need.

Typically, $12 \%$ of the available fuel energy is wasted as engine friction, with $25 \%$ of this total attributed to the piston ring pack [1]. Lubricant has been observed to be most degraded in the piston ring pack, especially around the top compression ring, due to the higher pressures, interaction with the combustion gases and higher temperatures in this region compared to the sump and elsewhere in the engine $[3,4]$. As the lubricant degrades, a change in the chemistry, in terms of additive depletion, oxidation and nitration $[5,6]$ and the viscosity $[7,8]$ results and these parameters can alter the lubricant film thickness experienced by the piston ring and thereby the piston ring friction. Oil film thickness (OFT) measurements of the lubricant between the piston ring and cylinder wall have been of great 
importance in the past to help validate mathematical models and provide information on the ring pack tribological performance.

There is little detailed knowledge of how the degradation of the engine lubricant with time, primarily by oxidation, affects the tribological behaviour within the piston ring pack and thereby impacts upon fuel economy and durability. A better understanding of this evolution in performance could be used to optimise lubricant oil drain intervals and thereby reduce lubricant waste and maintenance costs. The lubricant film thickness between the piston rings and the cylinder wall is fundamental to these crucial parameters.

Laser induced fluorescence (LIF) has been applied to measure lubricant film thickness between a piston ring pack and cylinder wall in a fired gasoline engine with lubricant ageing as a key factor alongside global engine operating conditions such as load, speed and temperature. The LIF measurement technique has been used in the past to measure films for fresh lubricant [9-12] but rarely for degraded lubricant because of poor optical response. To date, there have been three main methods used experimentally to quantify the piston ring OFT; electrical methods, LIF or the more recent ultrasound techniques, the latter being the only technique which is truly non-intrusive.

Electrical film thickness methods can either be conducting using electrical resistance and inductance transducers or capacitive. For resistance methods, by electrically insulating the piston ring from the rest of the piston and allowing an electric current to flow between the piston ring and the cylinder wall and measuring the resistivity, it is possible to obtain information on the lubricant film thickness [13-15]. The electrical resistance measured is proportional to the film thickness and a thicker film consequently produces a greater resistance. However, with such an examination of the films, a smooth plot of resistance against crank rotation is not easily observed. When the ring contacts the cylinder wall a short circuit is experienced and a complete breakdown of the films is observed at top dead centre (TDC) and bottom dead centre (BDC) where boundary lubrication results [16]. Alternatively, the distance between the piston ring and the cylinder wall can be measured with inductive transducers to give a measurement for the lubricant film thickness present. These transducers work on the principle of induction of a magnetic material where the separation between a wire coil and a magnetic material is dependent on the inductance [16]. One of the first reported lubricant film thickness measurements by the capacitance transducer method was achieved by Hamilton and Moore in 1974 [17, 18]. Lubricant film thicknesses between $0.4 \mu \mathrm{m}$ and $2.5 \mu \mathrm{m}$ were measured in a Petter AV1 diesel engine speeds from 900-1500 rpm with capacitance transducers mounted in the liner. It was found that lubricant cavitation provided an exaggeration of the film thickness. Moore later continued this research [19-22] with the lubricant film thickness between the piston ring and wall determined by measuring the electrical capacitance of the interface [19], using a similar technique of parallel plate capacitance as done earlier by Hamilton and Moore $[17,18]$. Moore stated that for thin films between $0.1 \mu \mathrm{m}$ and $1.0 \mu \mathrm{m}$ the capacitance method could be accurately calibrated using the simple parallel plate formula. Greater than $1.0 \mu \mathrm{m}$ and it was necessary to calibrate the system through other means, since the fringing field of electrons diverges the 
signal from theory [19]. Measuring lubricant film thickness with a capacitance transducer requires the dielectric constant of the lubricant to be known for correct calibration. As the lubricant degrades, the dielectric constant of the lubricant changes and as a result any existing calibration would not be valid. Also, the small transducer, and consequently small electric wires, did not survive for long periods due to the harsh environment of extreme temperature and pressure. Thermal expansion of the transducer wires and the glue used to hold the wires, to either the liner or the piston, caused reliability issues with transducers failing after short periods. During engine run-in, Moore [19] found that the signal was very random and erratic, which was found to be caused by short circuiting between the cylinder wall and the ring, as the lubricant films became thin enough to cause contact between the combined surface asperity heights. Shin et al. [23], struggled to get any signals and it was found that coating the transducers with aluminium oxide improved signal to noise ratio and reliability. Even though the technique can have its problems, there has been some success in the use of capacitance transducers. In a recent paper, Söchting and Sherrington [24] investigated the effect of engine load and lubricant viscosity on the minimum oil film thickness experienced at the piston ring to cylinder wall interface. It was found that the use of thinner lubricants generally provided a reduced minimum film thickness at the piston rings and the change in load had less of an effect than the change in viscosity. Similar results of the impact of engine load on oil film thickness were also observed by Tamminen et al. [25] and Takiguchi et al. [26]. Advances in capacitance transducer technology has led to responsive, accurate and low noise sensors that are insensitive to temperature changes being used in a fired engine and has simultaneously allowed the mapping of oil film thickness changes with ring twist to be measured [27].

Laser induced fluorescence (LIF) measurement of lubricant film thicknesses between the cylinder wall and the piston ring was first conducted by Ting in 1980 [28] and many subsequent followed [9, 10, 12, 29-37]. The principle uses laser light which absorbs in oil that has been doped with a fluorescent dye. The oil fluoresces at a different wavelength to the carrier signal and this return beam is converted into a voltage signal by using photomultiplier tubes. The intensity of the signal is related to the film thickness $[29,34]$ for a given lubricant and dye. The natural florescence of the lubricant has been examined for film thickness measurements without the use of a dye by Brown et al. [37], but the signal intensity would be too weak with degraded lubricants. The success of LIF lies in the calibration. In the past, researchers have etched grooves of known depths in the piston skirt as a means of calibration in situ, as Seki et al. [33], but Dearlove suggested that this method is ineffective since the grooves will wear [30]. Other researchers [29, 34, 38] have used lubricant samples of known film thicknesses statically and ex situ to calibrate the system. Initially, LIF was used as a means to achieve film thickness measurements $[10,28,29]$ but it was clearly seen that the system had the potential to investigate lubricant transport within the ring pack. The common system of shining a laser beam through the liner was criticised [26, 36, 39] for only providing information at one point and not valuable information about the oil film variation for the entire piston ring - cylinder wall interface, as the capacitance method was capable of doing when transducers were mounted in the ring $[23,26]$. This led to the introduction 
of multipoint LIF investigations, whereby multiple LIF probes were used at various positions on the cylinder liner to improve the understanding of the oil film profiles axially and radially around the piston $[9,34,40]$. The benefit of this outweighs the additional cost in extra probes and photomultiplier tubes, as Takiguchi et al. [34] found that a considerable amount of oil is supplied to the oil control ring at TDC for completion of the compression and exhaust strokes on the thrust side of the cylinder liner, and only at the end of the exhaust stroke on the anti-thrust side. Further improvements in multipoint LIF have seen a two dimensional LIF system being developed at Massachusetts Institute of Technology, USA by Thirouard et al. [39, 41].

LIF as well as capacitance film thickness measurements do have their limitations. They both cannot cope with lubricant cavitation, as both techniques require a lubricant film to be present so that a measurement can be made, and as a result anomalies are recorded.

Recently, a novel method of using ultrasound to measure the lubricant film thicknesses has been developed [42-47]. The method involves transmitting and measuring reflecting ultrasonic pulses between different densities of materials. The more different the densities of the materials, the more ultrasound signal will be reflected from their interface. So, if there is a film present between two solids, an ultrasonic pulse, directed at the film, will reflect from it. This offers a sensitive method of lubricant film thickness measurement, without the invasive approach of electrical transducers and LIF systems. The nature of the reflected pulse is proportional to the stiffness of the film and the film thickness can be determined from the stiffness, provided the acoustic characteristics of the film medium are known $[46,47]$. When investigating lubricant films between the piston ring and cylinder wall, this method uses an ultrasonic transducer attached to the outside of the liner. The transducer continuously pulses and any reflected pulses, from the piston as it passes, are recorded and analysed using Fast Fourier Transform analysis to determine the film thickness. This technique is capable of measuring thin films from 2 to $21 \mu \mathrm{m}$ [42] which is respectable when compared to capacitance and LIF techniques. Through strict calibration even thinner films between 0.5 and $1.3 \mu \mathrm{m}$ have been reported [47].

The ultrasonic method relies on the stiffness of the lubricant being known, similar to the dielectric constant that is need for capacitance transducers. These both rely on the lubricant being isotropic, as they are bulk parameters. There is some argument that the stiffness of the lubricant, and hence the bulk modulus and the dielectric, changes during operation when ring dynamics are considered and at the dead centres where ring reversal takes place and piston frictional forces are greater. The ultrasound technique can however detect some cavitation of the lubricant, since the method can detect lubricant and air (cavitation). The reflection can only take place off either the piston ring, for film thickness measurements, or air, for cavitation investigation. It cannot however, measure both cavitation and lubricant film thickness [48] simultaneously.

A summary of the published lubricant film thicknesses measured between the piston ring and cylinder wall using these techniques is presented in Table 1. This information is based on engine type and speeds, engine operating condition; either fired or motored, and the type of film thickness 
measurement technique that was employed. Some of the measured film thickness values are an approximate range deduced from the graphs in the relevant journal papers. From Table 1, the first striking piece of information is that lubricant film thickness measurements have rarely been conducted on gasoline engines, and as a result the tested engine speeds are low. Many commercially available diesel engines now have the technology to have higher speeds, approaching those of gasoline engines. The fact that diesel engines have been considered the choice for film thickness measurements by researchers could be due to the fact that diesel engines generally have a larger access area for probes than gasoline engines.

The three lubricant film thickness techniques have very similar film thickness measurement ranges. All methods do however, require a strict calibration procedure to ensure the film thickness measurements are accurate and repeatable. Capacitance and LIF have similar oil film thickness measurement ranges. The ultrasound technique currently has a much narrower range but is a newer technique being constantly developed. Sherrington [49] has suggested that film thickness methods in general will continue to be used for research and development purposes and as technology advances, the possibility of providing an online piston ring oil film thickness measurement with feedback control, to optimise the lubricant flow to the ring pack, looks promising.

For this research, LIF was chosen over the other film thickness methods as in the future it is envisaged that it can be combined with chemical analysis of the lubricant through the same optical window, thereby improving an understanding of piston ring pack lubricant degradation and lubrication during service.

\section{Experimental}

\subsection{Engine}

A Ricardo Hydra single-cylinder research gasoline engine was used for this study. The tribology of this engine has already been extensively characterised, for example [4, 54-57]. It is a naturally aspirated, gasoline, indirect injected engine based on a quarter of a commercially available $1998 \mathrm{cc}$, in-line, 4 cylinder General Motors engine introduced in 1988. The engine uses a production piston (AE reference 24024) and an equivalent production piston ring pack set (AE reference R23490). It is equipped with a single $86 \mathrm{~mm}$ bore wet liner housed in a barrel for liquid cooling. The parent engine has an integral metal bore and no separate cylinder liner. As a result, cylinder liners for this engine are bespoke cast iron components machined in-house. For this research, the cylinder liner was instrumented with three thermocouples on the thrust plane providing information on the TDC, mid-stroke and BDC liner temperatures which were used to monitor the operating oil temperatures in this region. These thermocouples were mounted approximately $1 \mathrm{~mm}$ from the running surface. The stroke length is 86 $\mathrm{mm}$ and the compression ratio in this configuration was 10.5:1 with a displacement of $499.5 \mathrm{cc}$. The engine has dual overhead camshafts and has four valves per cylinder; two inlet valves and two exhaust 
valves. The flywheel is directly connected to an electric dynamometer which can provide motoring operation and absorb torque under fired conditions. It can be operated fired up to a speed of $5000 \mathrm{rpm}$ and a maximum torque output of $36 \mathrm{Nm}$. The engine uses a dual external lubricant supply such that the crankshaft and the piston assembly can be lubricated with a separate lubricant to the valvetrain. This allows high quality lubricant to lubricate and protect the valvetrain whilst simpler formulations for test purposes can used to lubricate the crankshaft and piston assembly.

\subsection{LIF Equipment}

A Melles Griot Series 543 air-cooled Argon Ion laser was used as the source, operating at a blue wavelength of $488 \mathrm{~nm}$, which was the input to an optical arrangement, shown in the schematic of Figure 1, that measures source and fluorescence signals simultaneously via two photomultiplier tubes (PMT). Pyrromethene 567A dye was used as the fluorescent doping agent in the lubricant since it has a hydrocarbon chemical structure and requires no carrier fluid or solvent to mix into the test lubricant. This dye readily absorbs $488 \mathrm{~nm}$ laser emission well and in response fluoresces at a peak green wavelength of $543 \mathrm{~nm}$, giving a substantial Stokes wavelength shift of $55 \mathrm{~nm}$.

Blue and green colour filters were placed in front of the two PMTs, for the source and fluorescence signals respectively, to prevent cross contamination. A multimode fibre optic with a $105 \mu \mathrm{m}$ core diameter was used to transmit signals between the laser optics and the engine. A collimator probe, Figure 1 and Figure 2, was used to collect the incoming laser source and the returning fluorescence signal and align parallel before refocusing into either the sapphire window in the cylinder liner or, on return, into the fibre optic. This probe was mounted at the piston mid-stroke since this is where the maximum lubricant films are expected and, because the piston speed is at its maximum, the largest frictional power loss occurs. The probe was isolated from the engine coolant in a specially designed sleeve that passed through the Hydra barrel and the coolant sleeve to the window in the cylinder liner. The sleeve allowed the probe to be installed and removed from the engine without disturbing or disassembling the engine, Figure 3.

An increase in lubricant temperature reduces the fluorescence signal intensity, for a given film thickness, and as a result, fluorescence dye concentration plays an important part in defining the minimum lubricant film thickness (MOFT) that can be measured [29, 38]. With the degraded lubricants used in this study the opacity was equally important. As the lubricant degrades, the transparency reduces due to a combination of carbon deposit contamination from combustion and the lubricant oxidation process which produces darker coloured compounds [58]. So to be able to examine thin lubricant films static calibration and parametric tests established that $35 \mathrm{mg}$ per litre was needed for fresh lubricant and $100 \mathrm{mg}$ per litre for degraded lubricant. Such concentrations did not affect the lubricant chemistry or viscosity as confirmed through an initial investigation of a candidate lubricant with and without dye treatment by infrared spectroscopy and kinematic viscometric analysis at both $40{ }^{\circ} \mathrm{C}$ and $100{ }^{\circ} \mathrm{C}$. 


\subsection{Data Acquisition}

A shaft encoder with a resolution of 720 pulses per revolution was attached to the crankshaft to determine the piston and piston ring locations. Being a quadrature encoder, a crank angle resolution of 0.125 degrees was achieved. A 16-bit National Instruments (NI) analogue to digital card was used for data acquisition from the encoder and the PMT and an additional NI universal serial bus device was used to capture cylinder liner temperatures. LabVIEW codes were designed to capture the data from both acquisition devices simultaneously and to post process the data by averaging 50 engine cycles of data.

\subsection{Test Lubricant Samples}

A summary of the test lubricants used is provided in Table 2. All were Castrol Edge SAE 0W30 to ACEA C2/C3 and API SM/CF, with Sample A being a new fresh lubricant and B and C degraded samples. These were retrieved from customer vehicles with known histories by Mercedes Benz (MB) Car Leasing, Leeds, UK.

\subsection{Lubricant Chemical Analysis}

The lubricants were analysed to examine the state of degradation by Fourier Transform Infrared (FTIR) spectroscopy using a Perkin Elmer S100 Series FTIR, Figure 4. It can be clearly seen from the spectra that there is an increase in nitration (around $1630 \mathrm{~cm}^{-1}$ ), from combustion products, and carbonyl oxidation $\left(1800-1650 \mathrm{~cm}^{-1}\right)$ of degraded Samples B and C compared to the fresh Sample A.

\subsection{Lubricant Viscosity Analysis}

The viscosity of the lubricant changes as the lubricant degrades, which in turn should influence the lubricant film thickness experienced at the piston rings. As a result, the evolving viscosity of the lubricant is equally as important as the changes in lubricant chemistry through degradation. Modern lubricants are specified in terms of high temperature and high shear (HTHS) viscosity since engines operate at high temperatures and speeds. Standard HTHS values are recorded at a temperature of $150^{\circ} \mathrm{C}$ and a shear rate of $1.0 \times 10^{6} \mathrm{~s}^{-1}$ following the ASTM D4683 standard [59]. The test samples A, B and C were analysed at $100^{\circ} \mathrm{C}$ and this standard condition using a PCS Ultra shear viscometer since the lubricant experiences high shear rates at the piston rings. These results are displayed in Figure 6. It can be clearly seen that all samples undergo a decrease in viscosity both as the temperature increases and the shear rate increases. Since the lubricants are multigrade lubricants, they suffer from shear thinning at all temperatures as they contain polymer viscosity index improver additives. The minimum HTHS viscosity at $150^{\circ} \mathrm{C}$ and $1.0 \times 10^{6} \mathrm{~s}^{-1}$ in the SAE $0 \mathrm{~W}-30$ lubricant specification is shown in Figure 6 and it can be seen that as the lubricant degrades, through service, an increase in viscosity occurs. 


\subsection{Calibration}

The quantitative success of the LIF technique lies in careful calibration and to this end a purpose built calibration setup, Figure 7, was developed. A moveable vertical micrometer stage, with a sleeve to accept the collimator probe, was attached to a large rectangular reference block, and a linear variable differential transformer (LVDT) with a resolution of $0.25 \mu \mathrm{m}$ provided vertical displacement measurement of the stage. The sleeve contained an optical window similar to the window in the cylinder liner. A small oil bath containing part of a piston ring was used as the reflective surface for calibrating against, labelled as the 'calibration piece' in Figure 7, and the stage allowed the lubricant film thickness to vary from zero measurable film. This removed any uncertainty with reflectivity in the returned fluorescence as a real piston ring specimen was used. The oil bath was mounted on top of a $400 \mathrm{~W}$ hot plate, to facilitate calibration with increasing temperature. Calibration was undertaken five times at each test temperature for a specific test lubricant and then averaged, for film thicknesses from $0 \mu \mathrm{m}$ to 80 $\mu \mathrm{m}$, as measured on the output of the LVDT, since no film thickness above $80 \mu \mathrm{m}$ would ever be expected. The composite root mean square roughness of both the piston ring surface and the optical window in the sleeve was measured to be $0.08 \mu \mathrm{m}$, so realistically this was the minimum oil film thickness that could be measured by the system. A typical calibration profile is shown in Figure 8 and clearly demonstrates the influence of lubricant degradation, more specifically lubricant opacity, when comparing a fresh lubricant, which has been doped with $35 \mathrm{mg} / 1$ of dye to a degraded lubricant with $100 \mathrm{mg} / \mathrm{l}$ both at a test temperature of $80^{\circ} \mathrm{C}$.

\subsection{Testing Procedure}

The lubricant samples were used on the Hydra engine to investigate the influence of lubricant degradation on the minimum lubricant film thickness experienced by the piston ring. The lubricants were tested in the Ricardo Hydra at four engine speeds (1000, 2000, 3000 and $4000 \mathrm{rpm}$ ) and three engine loads ( $0 \%$ (motored), $50 \%$ and $100 \%$ of maximum torque). The engine was operated under fired conditions at a stoichiometric air fuel ratio (AFR) of 14.7:1. The AFR was measured from the exhaust gases using a Horiba MEXA-554JE Automotive Emission Analyser.

Once the engine was at the required operating condition, it was run for 30 minutes to ensure the engine temperature was stabilised before the data acquisition commenced. Data for the piston ring oil film thickness profiles over at least 100 consecutive engine cycles was then taken. To check for repeatability and gain test confidence, a random selection of test conditions was repeated. Once the test matrix was completed for one lubricant the next test lubricant was studied only after a double lubricant flush and drain procedure. During this procedure, the test lubricant was drained from the engine, 2 litres of fresh lubricant was added to the engine sump and the engine operated with this lubricant for approximately one hour motored at $2000 \mathrm{rpm}$. This lubricant was then drained and then 2 litres of the next test lubricant was used to flush the engine of the previous lubricant using the same technique, until finally this was drained and 2 litres more of a fresh batch of the test lubricant was poured into the sump 
ready for examination. At each lubricant drain, a new engine oil filter was fitted. Performing the oil flush in this manner ensured no cross contamination of lubricant occurred.

\section{Results and Discussion}

The lubricant film thickness observed by the transducer in the cylinder wall across all four gasoline engine strokes for Sample A at $1000 \mathrm{rpm}$ and $50 \%$ load is presented as Figure 9. The position of the piston rings and the piston direction are superimposed on the figure. The position of the piston and the piston rings in the following figures was accurately determined using a Solidworks computer aided design software model of the engine setup and cross referencing with the encoder shaft position data. First, it can be seen that the piston direction greatly influences the observed oil film thickness profile, with the profile on the piston downstrokes (power and inlet) clearly different to that on the piston upstrokes (compression and exhaust). It must be noted that although a single profile of oil is observed across the piston ring pack, between the piston rings the LIF signal will combine any lubricant on the piston lands, lubricant mist and lubricant on the cylinder wall (i.e. the optical window) in unknown proportions. For this reason the focus of this research was only the films observed under the piston ring, which is the minimum oil film thickness (MOFT). Also the MOFT at the oil control ring (OCR) was taken as the film experienced under the upper oil control rail since the bottom flank of the ring groove has a chamfer which sometimes created a reservoir for local oil films that saturated the film under the lower control ring, making exact identification of the MOFT under this rail impossible.

The results for each lubricant sample were averaged over 50 complete engine cycles and the standard deviation was found to be $0.7 \mu \mathrm{m}$ at the piston rings. The standard error was found to be an impressive $0.10 \mu \mathrm{m}$ over the 50 engine cycles. The standard deviation measures the amount of variability from the mean whereas the standard error measures how far the mean of the data is from the population mean and therefore describes how precise the mean is. Due to the scale of the following results, the error of $0.1 \mu \mathrm{m}$ is not displayed on the figures. Also, all the stated temperature recordings were at the mid-stroke probe position.

Figure 10 displays the piston ring MOFT results when the engine was motored at a speed of 1000 $\mathrm{rpm}$, where the steady state mid-stroke temperature was $30^{\circ} \mathrm{C}$. Figure 11 shows the overall piston ring MOFT results at the same conditions as Figure 9, where the engine was fired at $1000 \mathrm{rpm}$ and $50 \%$ load with a mid-stroke temperature of $60^{\circ} \mathrm{C}$. By comparing the two figures, Figure 10 and Figure 11 , it can be seen that the firing action reduces the MOFT experienced by the piston ring pack substantially. The addition of the fuel, and consequently combustion energy, will result in higher cylinder pressures that contribute to thinner films along with the increase in cylinder temperatures. The same was observed for a combination of different engine speeds and operating conditions. The films measured at the compression ring for the compression and exhaust stroke remained consistently 
small regardless of whether the engine was firing or motoring, adding to the long held belief that it operates under starved conditions.

The lubricant films at the top two rings during the upstrokes (compression and exhaust) we found to be thinner than the lubricant films during the downstrokes (inlet and power) and this was fairly evident regardless of operating condition, but not necessarily the same trend follows for the OCR.

The second ring is a Napier type ring with a linear tapered profile designed to scrape excess lubricant from the cylinder wall on the downstroke. The piston ring profiles were measured using a Taylor Hobson Talysurf Profilometer which uses a contacting stylus. As can be seen from the measured ring profiles after testing, Figure 12, wear occurs readily at the lower edge of the ring making the profile more symmetrical. As a result of this and the superior lubricant supply at the inlet at midstroke on the downstroke from the OCR compared to the upstroke from the compression ring, larger film thicknesses are observed on the downstrokes (inlet and power) than the upstrokes (compression and exhaust).

In terms of investigating the effect of lubricant degradation across the complete engine cycle, during motored operation, the films for the fresh lubricant, Sample A, presented thinner films when compared to the most degraded lubricant, Sample C. However, under fired conditions Sample A presents a thicker film under the ring pack than the degraded samples during the inlet and power strokes. Sample A has lower HTHS viscosity values than any of the degraded lubricants, see Figure 6, and the lower lubricant viscosity will facilitate better lubricant flow into the ring pack, explaining why greater films are observed at the scraper and oil control rings. Since the lubricant flow is not directly measured however, this is only a hypothesis. The compression ring profiles are similar in thickness regardless of the quality of the lubricant or the stroke, reinforcing its high level of lubricant starvation as the dominant factor.

The piston ring MOFT results presented in Figure 13 show the effect of increasing the engine speed at maximum load. Since there was no substantial variation between the two downstrokes (inlet and power) and also between the two upstrokes (compression and exhaust), only the compression and power stroke data is presented. It can be seen that as the engine speed is increased, greater film thicknesses are generally experienced across the piston ring pack. As the engine speed increases, the crankshaft rotational speed increases and the rate of lubricant throw from the crankshaft bearings and the connecting rod is greater. So there is more lubricant available on the lower cylinder wall to the ring pack and this combined with increased lubricant entrainment due to the higher sliding speeds will yield thicker films under the rings. So, it is acceptable to state that at the lower engine speeds, oil availability is critical and as the speed increases the MOFT increases.

The film thickness increases as the engine speed increases on the compression stroke whereas on the power stroke this is evident at lower speeds, but there is a reversal in this trend at $4000 \mathrm{rpm}$. It is not known why exactly this occurs, other than the increase in chamber pressures has contributed to a lower lubricant viscosity and hence a thinner piston ring MOFT. However, as the speed increases the influence of the lubricant degradation becomes more apparent. The most degraded lubricant, Sample C, shows 
consistently higher film thickness profiles as the speed increases. Here the HTHS viscosity of the lubricant is appreciably more and therefore it is acceptable to state that at the higher engine speeds, the lubricant viscosity and hence lubricant degradation is more dominant. Sample B, being of a similar HTHS viscosity as Sample A, also shows less difference at the highest test engine speed, emphasising the fact that the viscosity of the lubricant is more dominant at the higher engine speeds. Admittedly, there is a breakdown of this statement for Sample B at $3000 \mathrm{rpm}$ and $90{ }^{\circ} \mathrm{C}$ oil temperature during the powerstroke but this could simply be down to the irregular and complex nature of the combustion process where no two engines cycles are the same.

Using the HTHS data measured for each test lubricant, the instantaneous measured piston ring MOFT was plotted against the HTHS value at $4000 \mathrm{rpm}$ and $100 \%$ load for the compression, scraper and oil control rings in Figure 14, Figure 15 and Figure 16 respectively. By calculating the instantaneous velocity at the LIF probe position for each piston ring and knowing the MOFT at the ring at the same position, it was possible to determine the instantaneous shear rate of the film measured. This test condition was chosen since the mid-stroke liner temperature, $95{ }^{\circ} \mathrm{C}$, was the closest to the measured HTHS temperature of $100^{\circ} \mathrm{C}$, Figure 5. It can be seen from the results, that there is very good correlation between the measured piston ring MOFT and the HTHS value. Generally, the higher HTHS lubricant, Sample C, presented the greatest film thicknesses compared to either Sample A or B at the rings, regardless of engine stroke.

The data presented in Figure 17 shows the influence of increasing the engine load on the piston ring MOFT during the power stroke at 1000 and $3000 \mathrm{rpm}$. A combination of wider throttle openings and fuel addition will improve the combustion capacity and hence engine torque. Cylinder temperatures will also be increased and a reduction in the film thickness results, regardless of engine speed. It can also be seen that the influence of lubricant degradation becomes more apparent at higher engine speeds and loads, notably at $3000 \mathrm{rpm}$ and 100\% load (Figure 17), where the highly degraded Sample C yields thicker films across the entire ring pack than the fresh Sample A. This suggests that at the extremities of high temperature, high cylinder (pressure) loading and high engine speeds, the lubricant viscosity is dominant.

\section{Conclusions}

The LIF technique has been developed further in a fired gasoline engine to investigate the influence of lubricant degradation on the piston ring to cylinder wall lubricant film thickness. A wide range of engine operating conditions was tested with a selection of degraded lubricants. The results were obtained from the Ricardo Hydra gasoline engine and the following conclusions can be drawn: 
- The film thickness of a degraded lubricant can be measured even during fired engine operation with results that have very good spatial resolution due to a combination of high optical resolution and high speed data acquisition.

- Lubricant film thickness profiles of all four engine strokes showed that there is a difference between the profiles which depends upon the direction of the piston motion and it was found that the ring profiles and lubricant starvation were the main cause of this.

- The top compression ring was found to operate in near-starved lubricant conditions and it was shown how such small films can change with a function of engine speed, load and crank angle.

- Thinner lubricant films were observed on the compression and the exhaust strokes for the top two rings for the intake and power strokes. This occurred during both firing and motoring operation.

- The introduction of firing, and hence increased cylinder pressure and temperature, reduces the film thickness of the lubricant under the rings. A continuous increase in engine loading reduces the film thickness further regardless of engine speed.

- At the slower engine speeds, the rate of lubricant throw from the crankshaft and the connecting rod is much less than at higher speeds. As a result, at slower engine speeds the availability of lubricant is less and hence the film thickness in the ring pack is smaller. However, as the engine speed increases a greater availability of lubricant on the cylinder liner contributes to a higher film thickness. This is true regardless of lubricant quality.

- At the higher engine speeds, the high temperature and high shear rate, the viscosity of the lubricant, was found to be more dominant in influencing the extent of thicker piston ring MOFT than the engine speed.

- Generally, the measured piston ring MOFT correlated well with the HTHS values of the test lubricants.

- As the lubricant degrades, the lubricant films were found to increase in thickness across the entire piston ring pack. This would ultimately affect piston assembly friction and have implications for overall engine performance, fuel economy and exhaust gas emissions. 
$\underline{\text { List of Tables }}$

\begin{tabular}{cccccc}
\hline Reference & Method & $\begin{array}{c}\text { Engine } \\
\text { Type }\end{array}$ & $\begin{array}{c}\text { Engine } \\
\text { Operation }\end{array}$ & $\begin{array}{c}\text { Engine } \\
\text { Speed }(\mathbf{r p m})\end{array}$ & $\begin{array}{c}\text { OFT range } \\
(\boldsymbol{\mu m})\end{array}$ \\
\hline$[24]$ & Capacitance & Diesel & Fired & 2000 & $4.0-12.0$ \\
{$[50]$} & Capacitance & Gasoline & Motored & 1000 & $1.6-5.8$ \\
{$[51]$} & Capacitance & Diesel & Motored & $200-800$ & $5.0-13.0$ \\
{$[20]$} & Capacitance & Diesel & Motored & 1000 & $0.9-2.0$ \\
{$[52]$} & Capacitance & Diesel & Motored & $1300-1400$ & $0.2-8.2$ \\
{$[33]$} & LIF & Diesel & Fired & $1500-2000$ & $0.5-4.0$ \\
{$[12]$} & LIF & Diesel & Fired & 1000 & $0.9-4.7$ \\
{$[34]$} & LIF & Diesel & Fired & 2000 & $0.6-3.5$ \\
{$[45]$} & Ultrasound & Diesel & Motored & 840 & $6.0-8.0$ \\
{$[53]$} & Ultrasound & Gasoline & Fired & 2230 & $3.0-11.0$ \\
{$[60]$} & Ultrasound & Gasoline & Fired & 3200 & $0.2-5.0$ \\
\hline
\end{tabular}

Table 1: A summary of the range of piston ring pack lubricant film thickness measurements by previous researchers

\begin{tabular}{|c|c|c|c|}
\hline Sample & Description & Lubricant & Usage \\
\hline A & MB fresh oil & \multirow{3}{*}{$\begin{array}{l}\text { Castrol Edge } \\
\text { SAE 0W-30 } \\
\text { Gasoline oil }\end{array}$} & Fresh \\
\hline B & MB medium size car & & 5470 miles $(8803 \mathrm{~km})$ \\
\hline $\mathbf{C}$ & MB sports car & & 9156 miles $(14735 \mathrm{~km})$ \\
\hline
\end{tabular}

Table 2: A summary of the test lubricants 


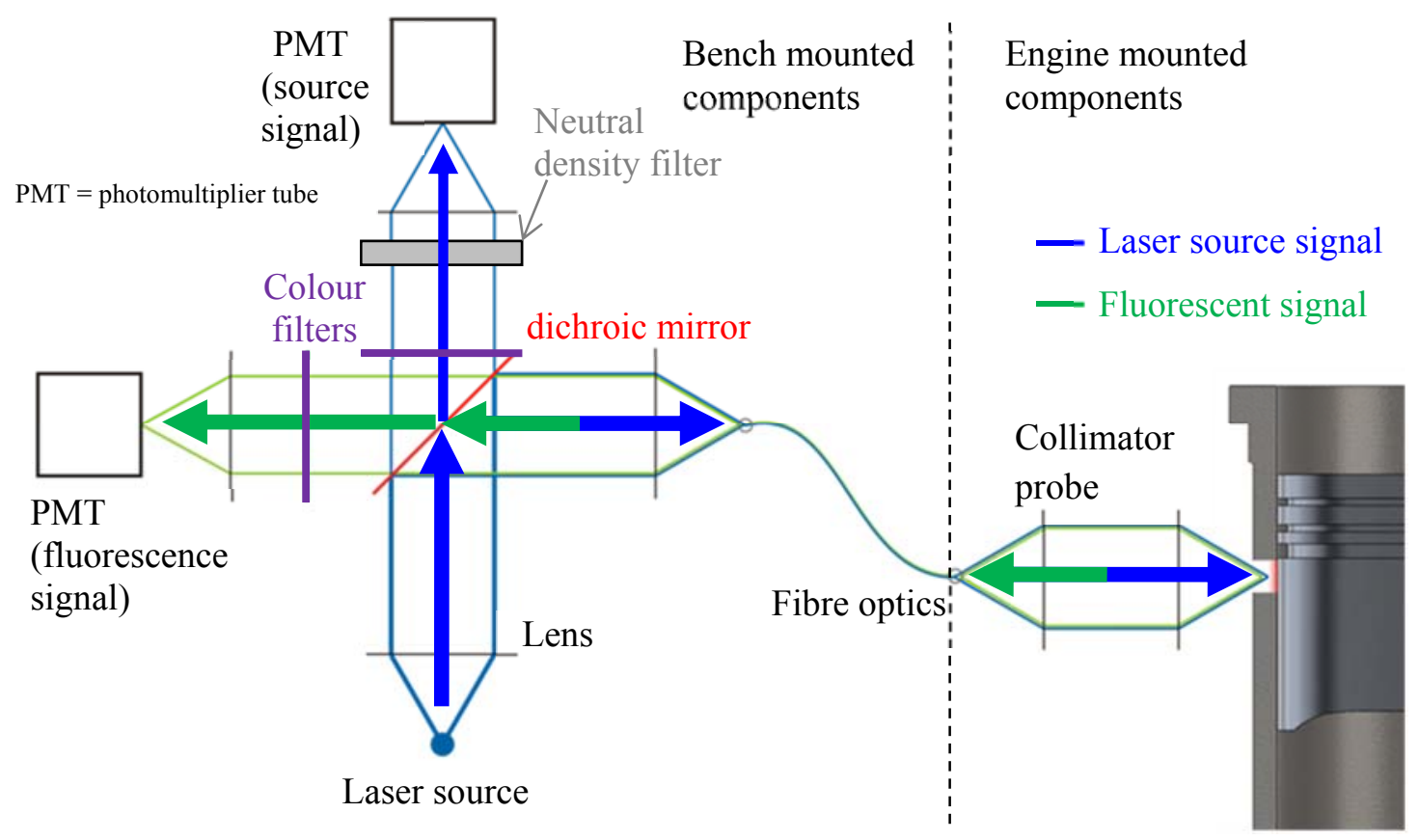

Figure 1: LIF Optical Setup

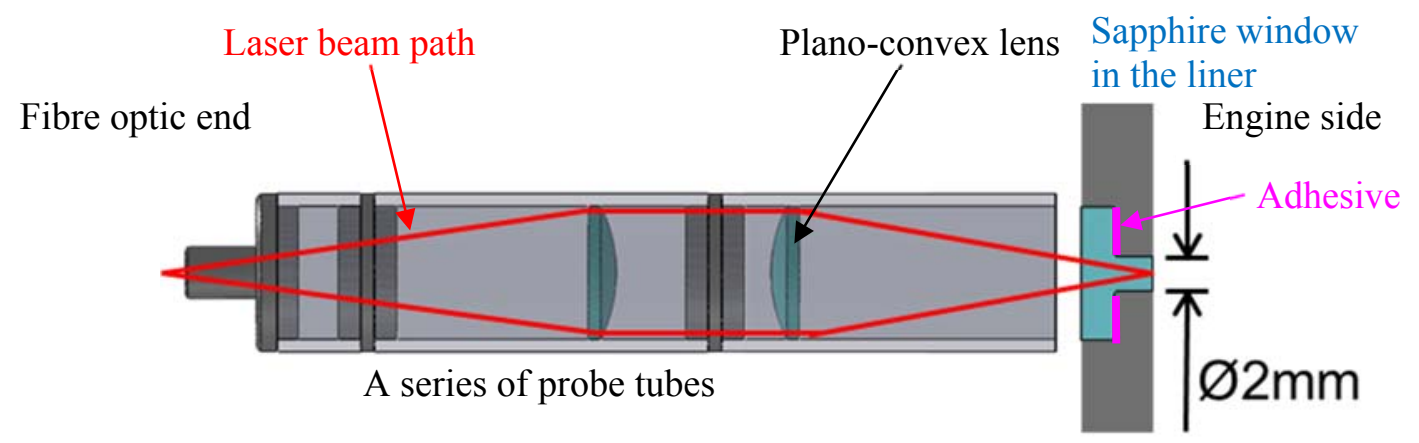

Figure 2: Collimator probe and cylinder liner window 


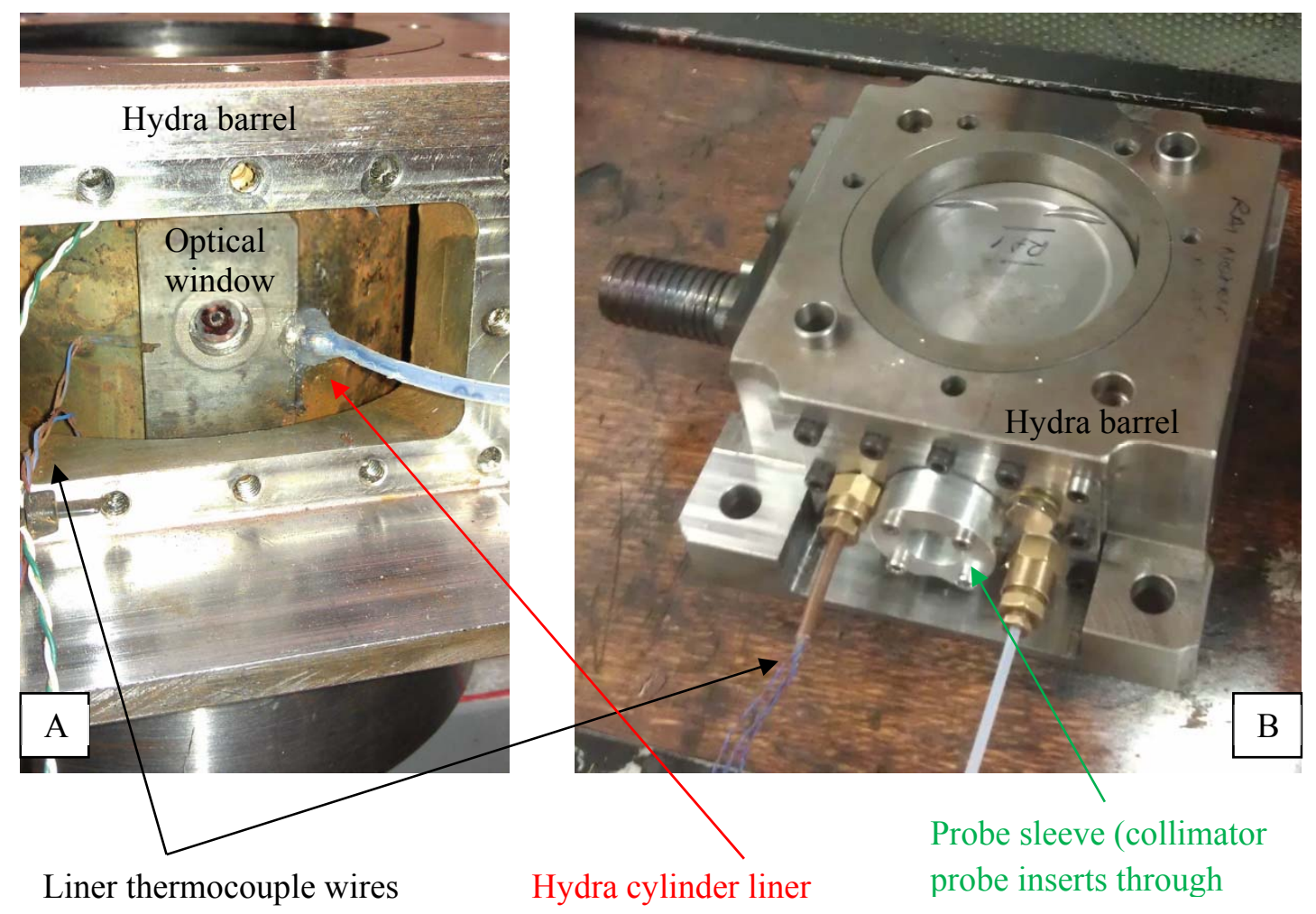

Figure 3: Images showing; A) the Hydra liner thermocouple wires and the optical window, and B) the collimator probe sleeve in the barrel

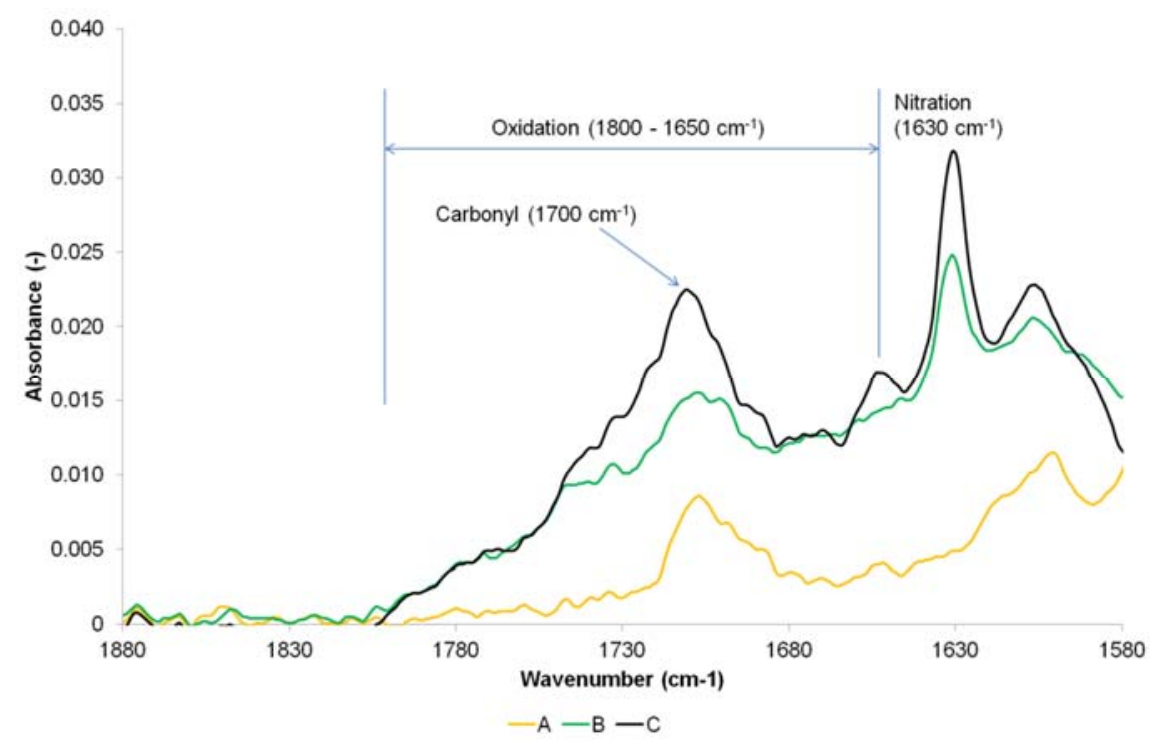

Figure 4: FTIR spectra of test lubricants focussing on oxidative degradation 


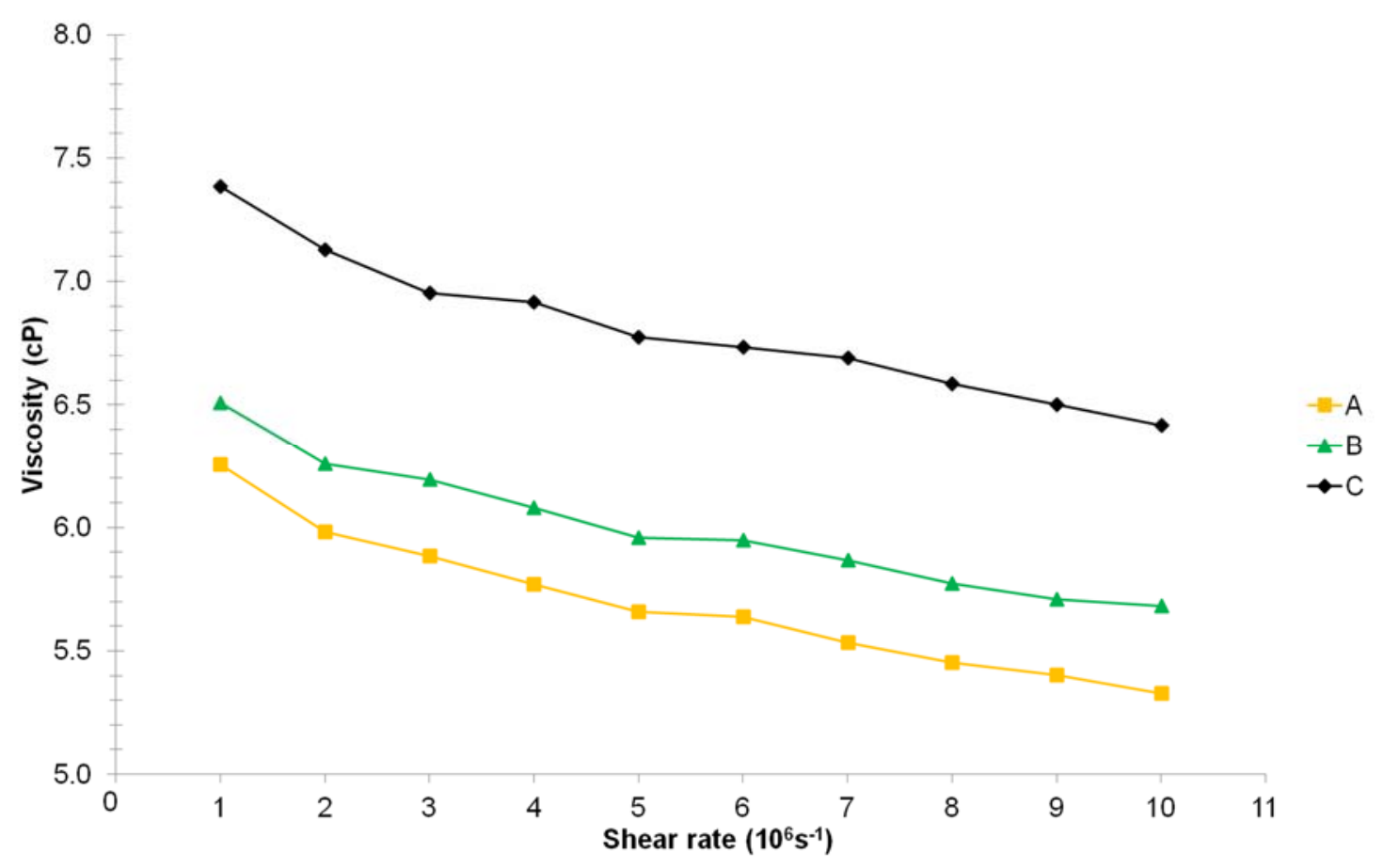

Figure 5: HTHS viscosity of test lubricants at $100^{\circ} \mathrm{C}$

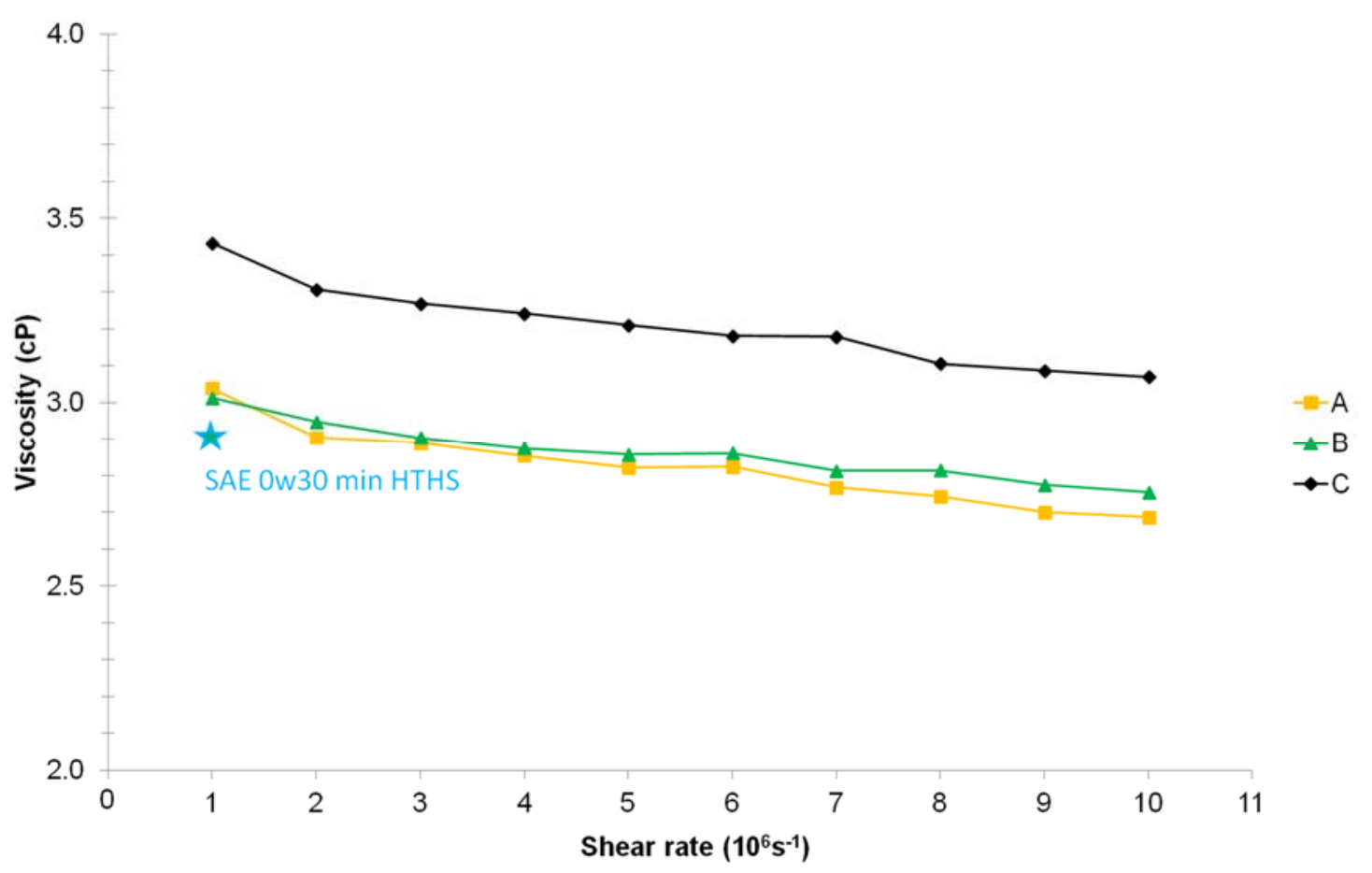

Figure 6: HTHS viscosity of test lubricants at $150^{\circ} \mathrm{C}$ 


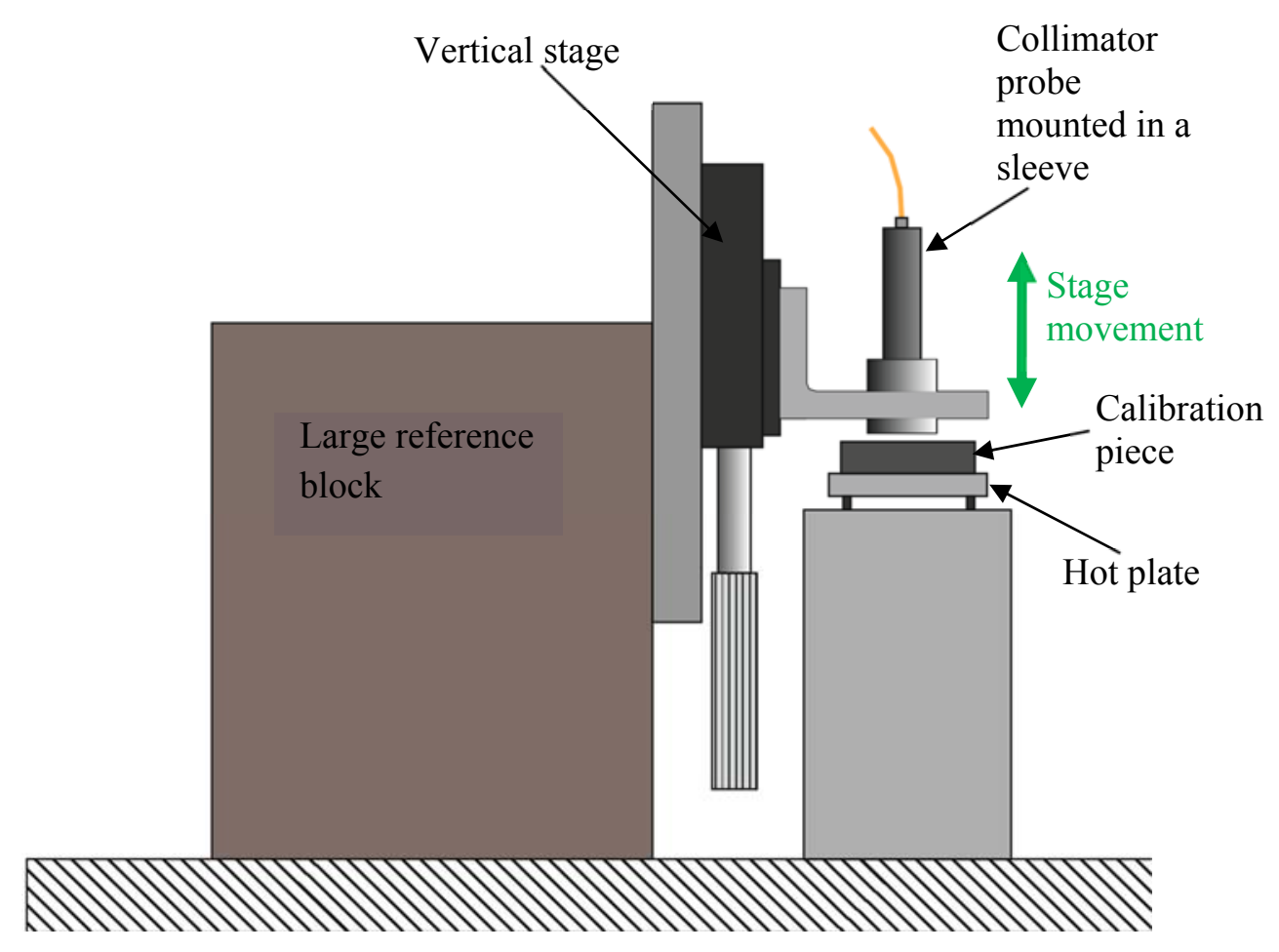

Figure 7: Calibration setup designed and manufactured

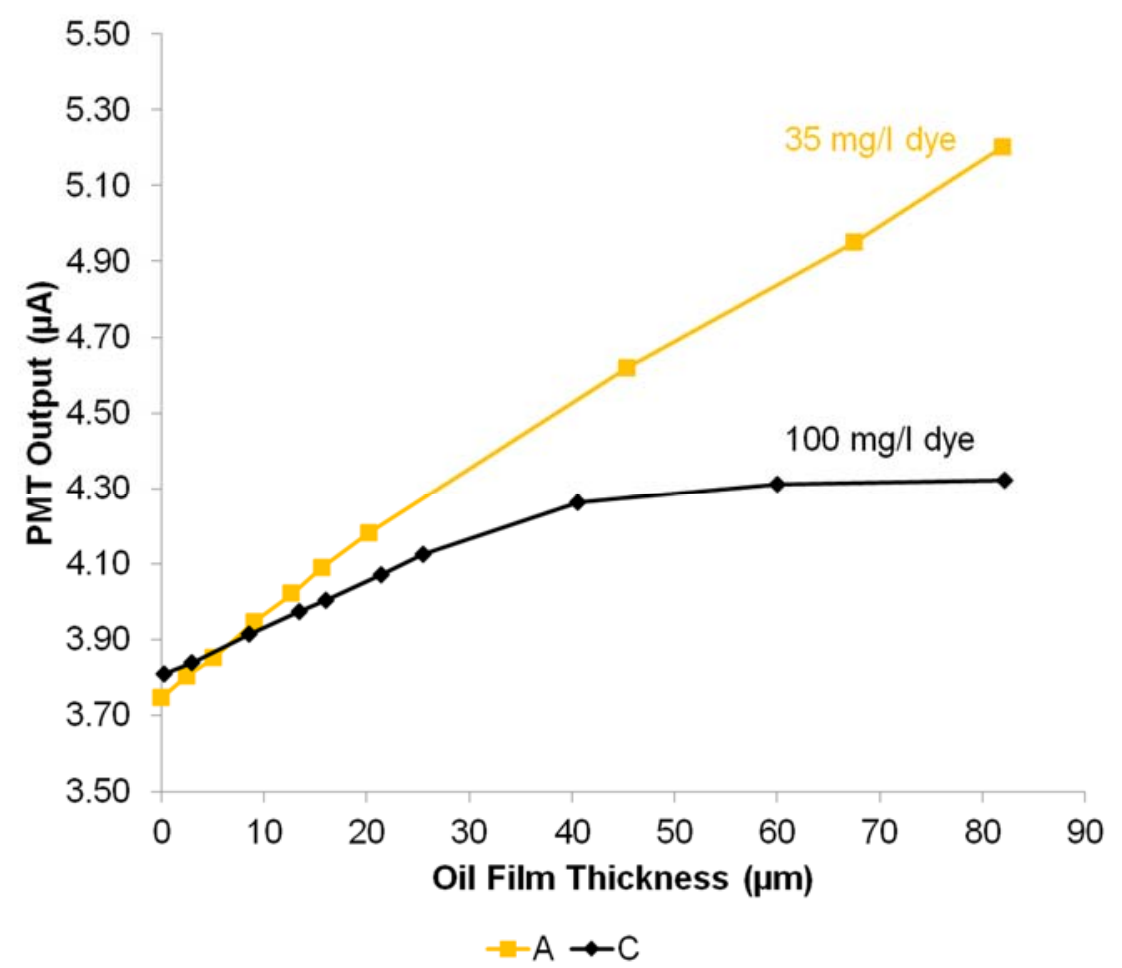

Figure 8: Typical calibration result for Sample A (fresh) and Sample C (degraded) lubricants 

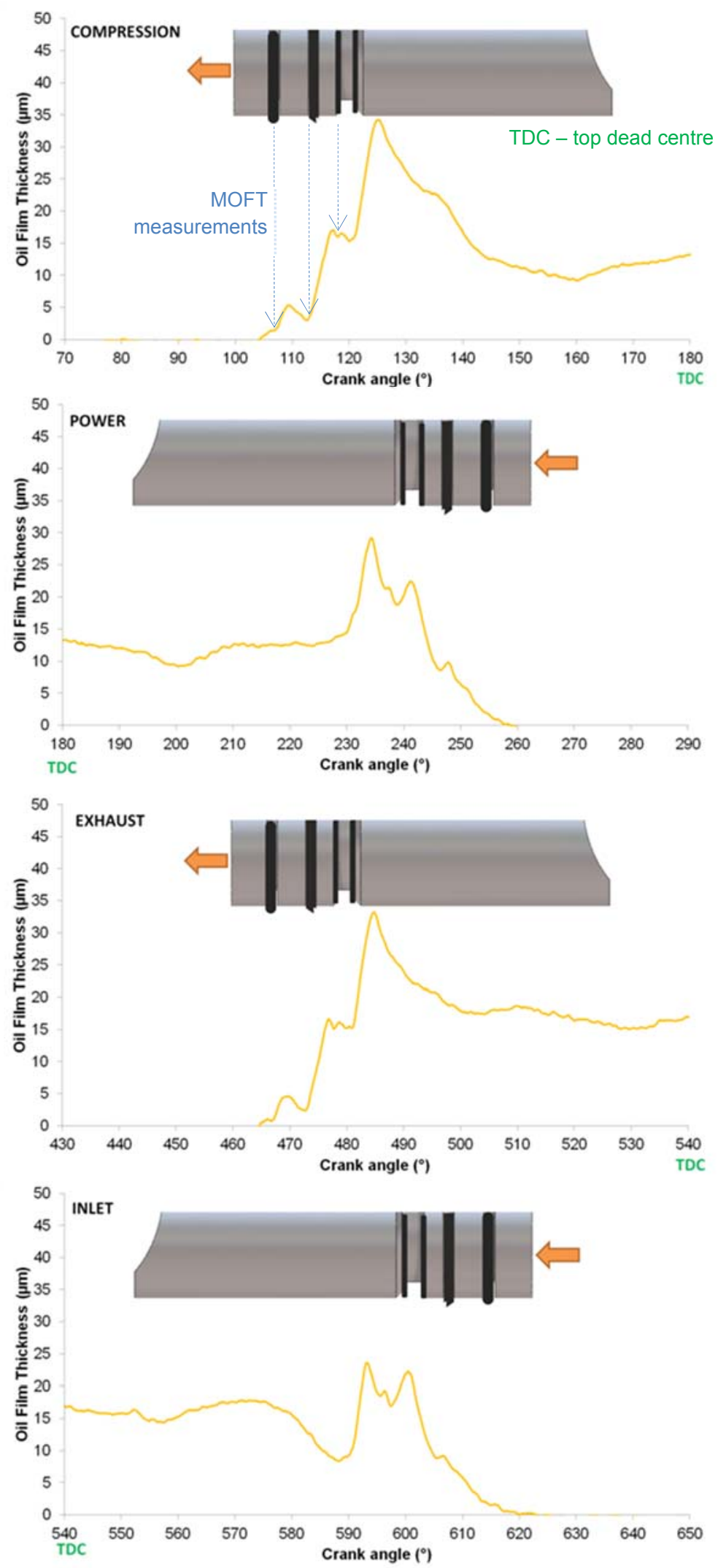

Figure 9: Typical 4 stroke LIF profile for Sample A at $1000 \mathrm{rpm}, 50 \% \mathrm{load}, 60{ }^{\circ} \mathrm{C}$ 


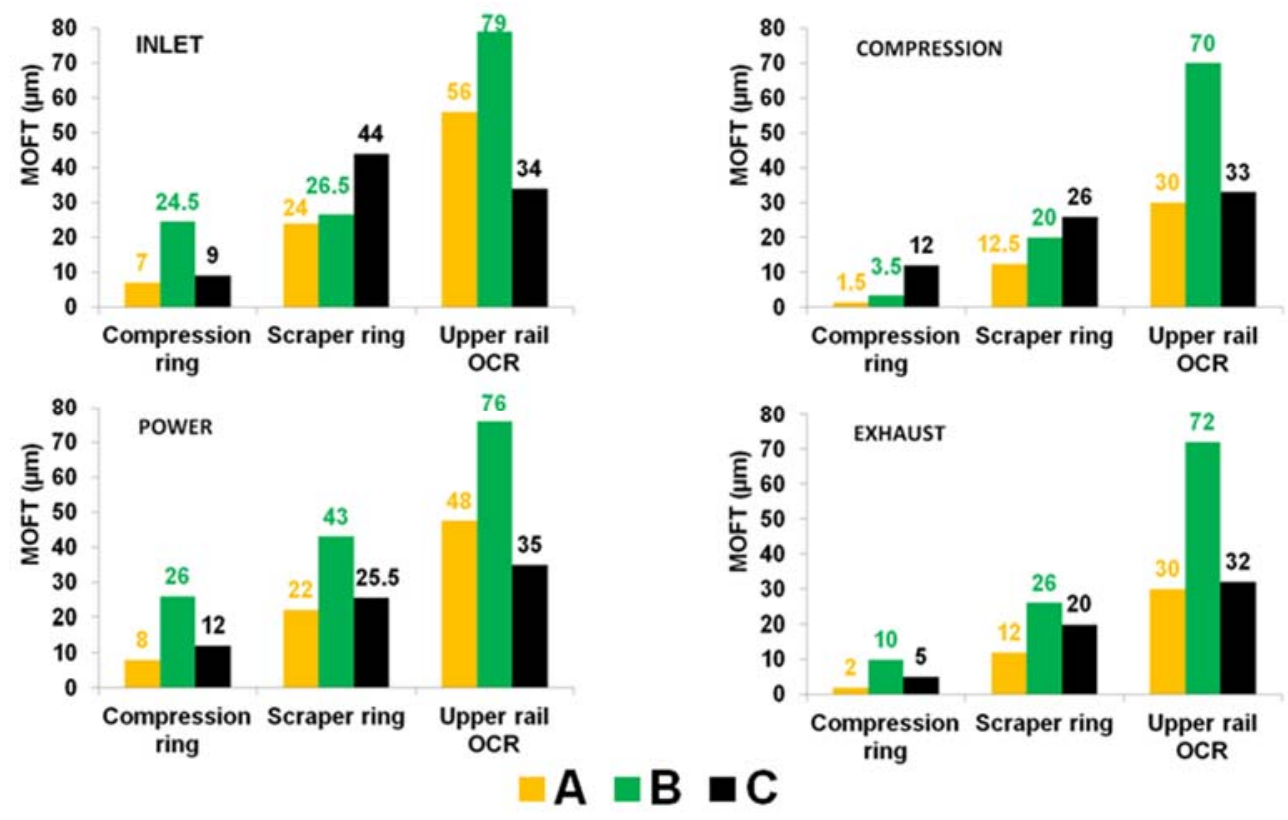

Figure 10: Piston ring MOFT at $1000 \mathrm{rpm}$, no load (motoring), $30{ }^{\circ} \mathrm{C}$
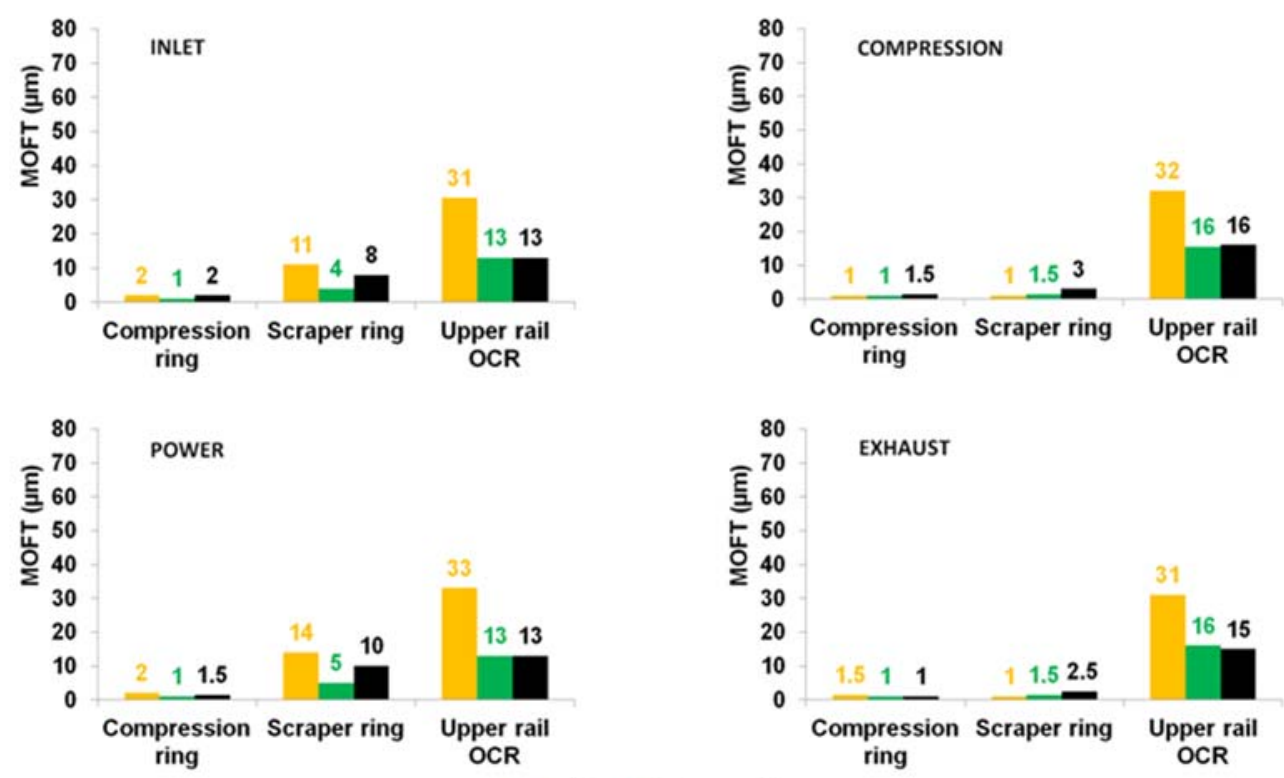

$A \backsim B \backsim C$

Figure 11: Piston ring MOFT at $1000 \mathrm{rpm}, 50 \%$ load (firing), $60{ }^{\circ} \mathrm{C}$ 

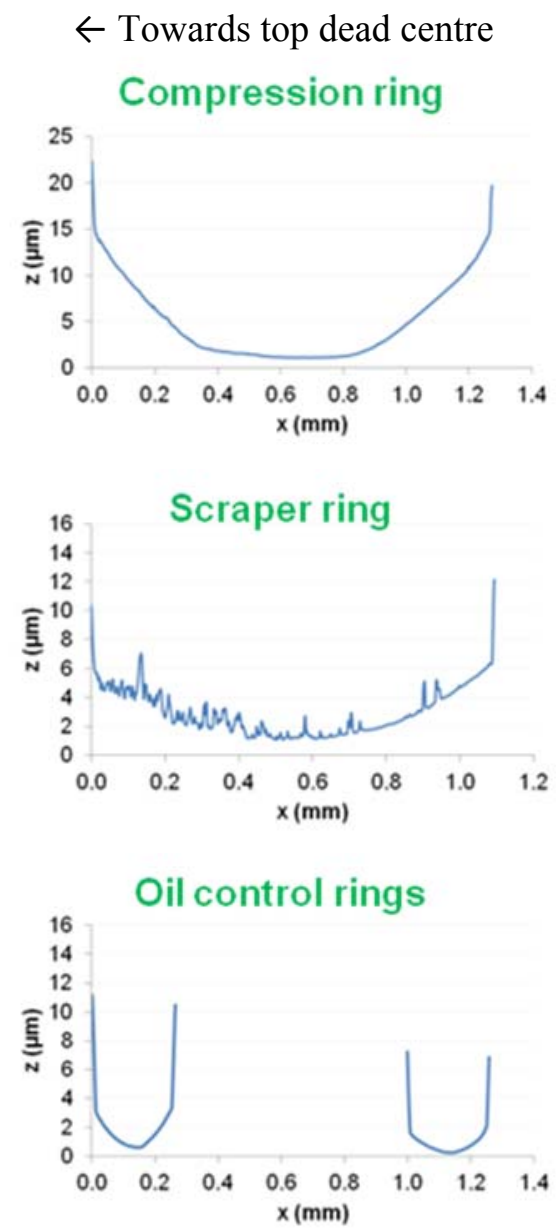

Figure 12: Measured piston ring profiles after LIF measurement testing 
$1000 \mathrm{rpm}, 65^{\circ} \mathrm{C}$ mid-stroke temperature:

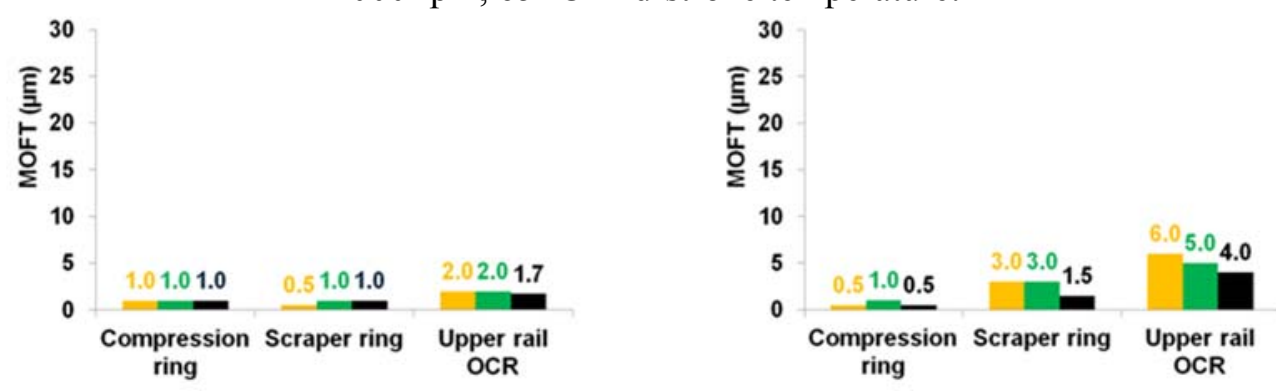

$2000 \mathrm{rpm}, 75^{\circ} \mathrm{C}$ mid-stroke temperature:
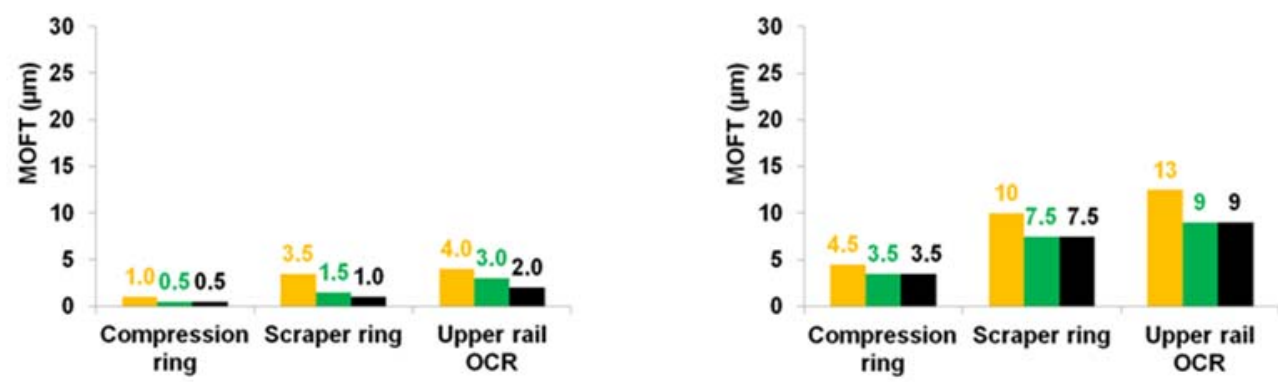

$3000 \mathrm{rpm}, 90{ }^{\circ} \mathrm{C}$ mid-stroke temperature:
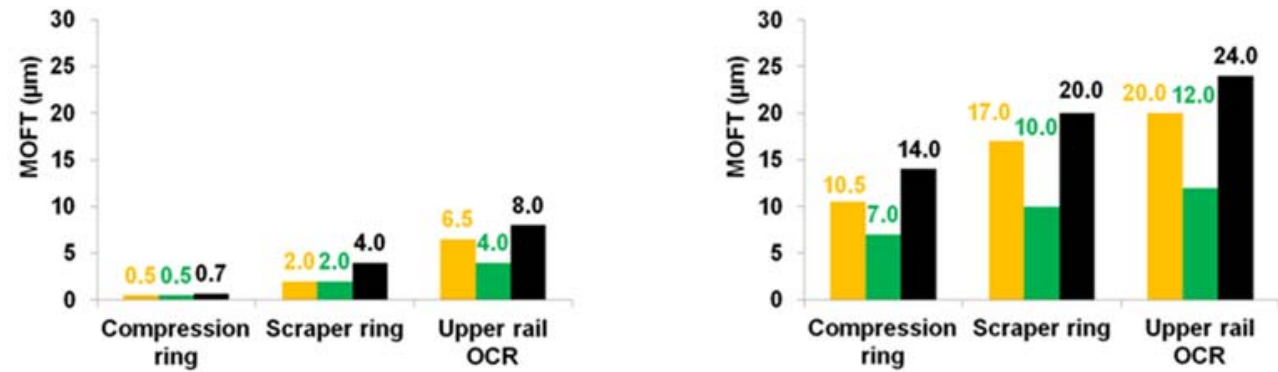

$4000 \mathrm{rpm}, 95{ }^{\circ} \mathrm{C}$ mid-stroke temperature:
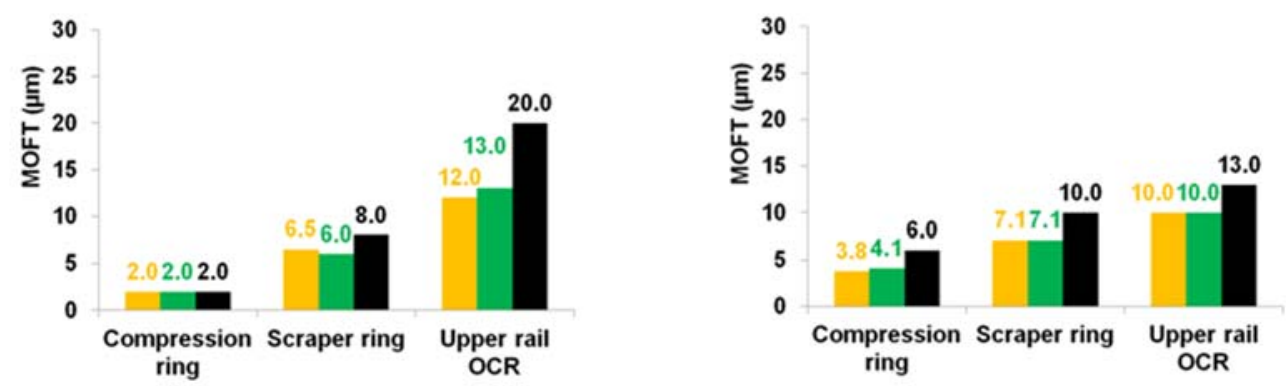

\section{$A \backsim B \backsim C$}

Figure 13: The effect of engine speed at maximum load on piston ring MOFT 

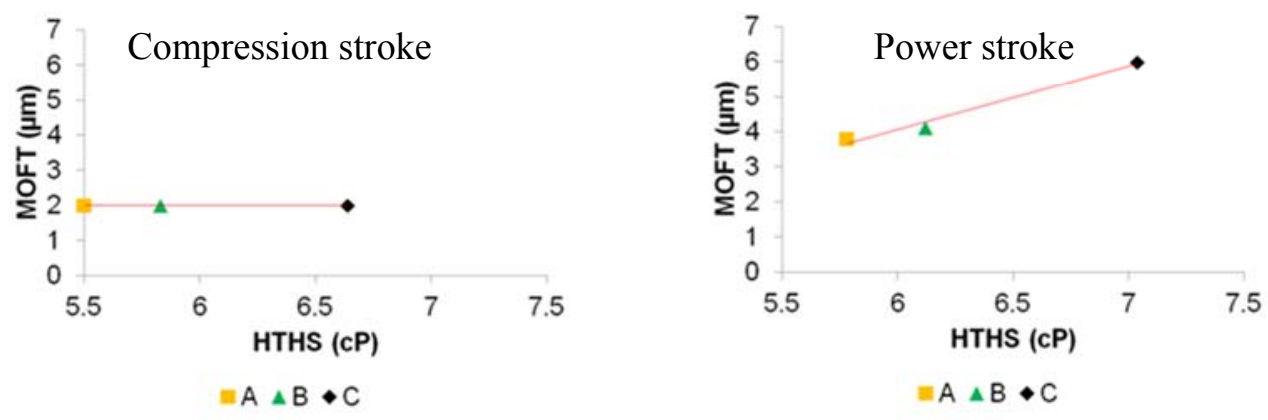

Figure 14: MOFT against HTHS - compression ring, $4000 \mathrm{rpm}, 100 \% \mathrm{load}, 95{ }^{\circ} \mathrm{C}$
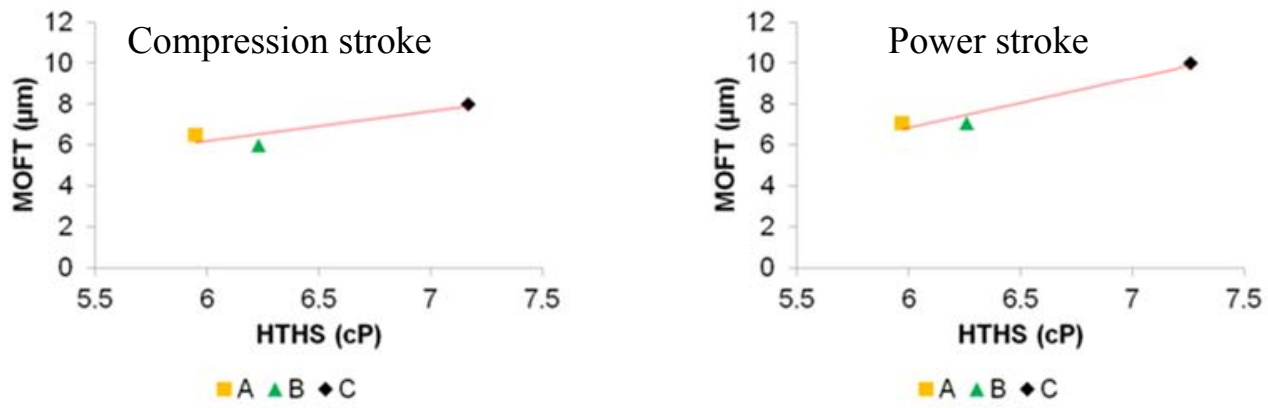

Figure 15: MOFT against HTHS - scraper ring, $4000 \mathrm{rpm}, 100 \%$ load, $95{ }^{\circ} \mathrm{C}$
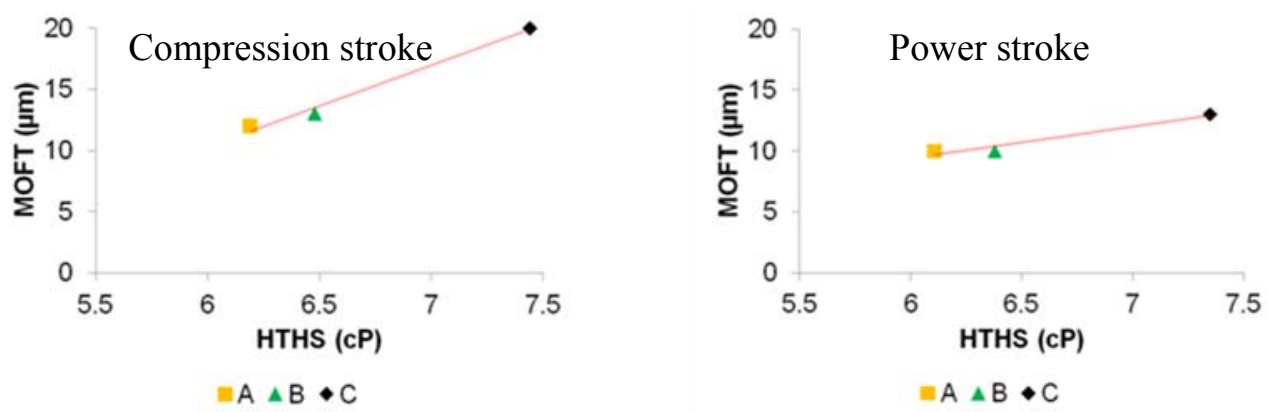

Figure 16: MOFT against HTHS - oil control ring, $4000 \mathrm{rpm}, 100 \% \mathrm{load}, 95^{\circ} \mathrm{C}$ 


\section{POWER STROKE}

$1000 \mathrm{rpm}$, no load, $30^{\circ} \mathrm{C}$

mid-stroke temperature:

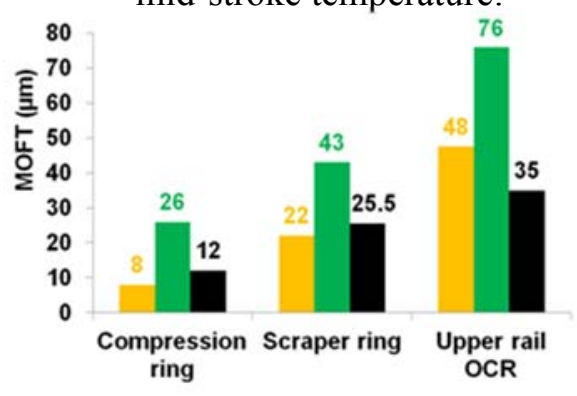

$1000 \mathrm{rpm}, 50 \%$ load, $60{ }^{\circ} \mathrm{C}$ mid-stroke temperature:

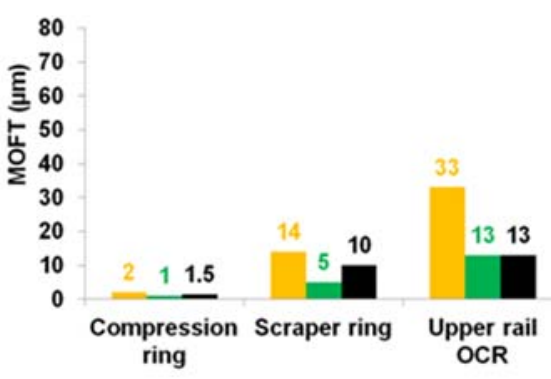

1000 rpm, $100 \%$ load, $65^{\circ} \mathrm{C}$ mid-stroke temperature:

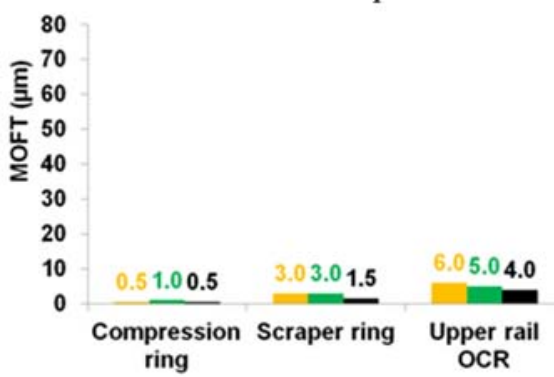

3000 rpm, no load, $45^{\circ} \mathrm{C}$ mid-stroke temperature:

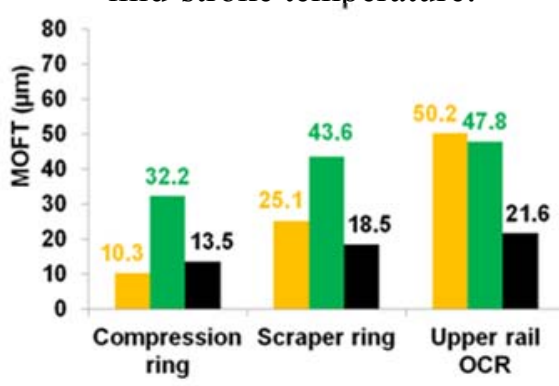

$3000 \mathrm{rpm}, 50 \%$ load, $85{ }^{\circ} \mathrm{C}$ mid-stroke temperature:

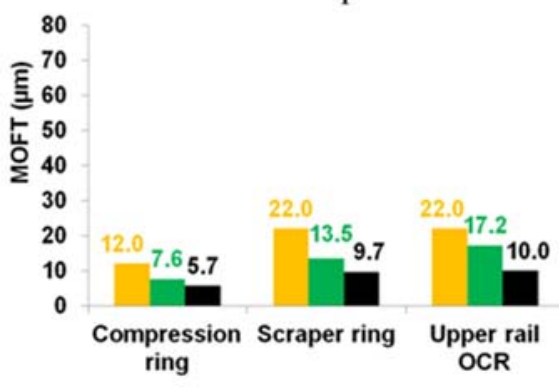

$3000 \mathrm{rpm}, 100 \%$ load, $90{ }^{\circ} \mathrm{C}$ mid-stroke temperature:

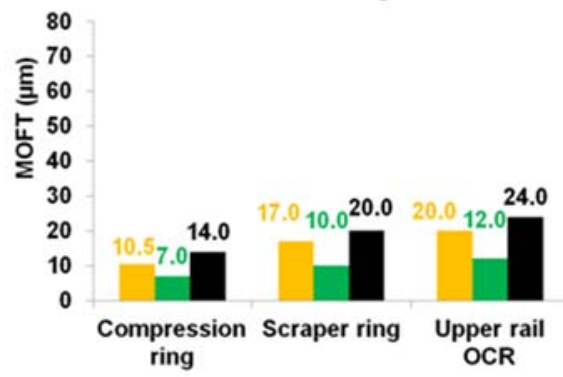

\section{$A=B=C$}

Figure 17: The effect of engine load on piston ring MOFT at engine speeds of 1000 and 3000 rpm 


\section{References}

1. Tung, S.C. and M.L. McMillan, Automotive tribology overview of current advances and challenges for the future. Tribology International, 2004. 37(7): p. 517-536.

2. Hoshi, M., Reducing friction losses in automobile engines. Tribology International, 1984. 17(4): p. 185-189.

3. Lee, P.M., Lubricant Degradation, Transport and the Link to Piston Assembly Tribology. PhD Thesis, in School of Mechanical Engineering. 2006, University of Leeds: Leeds.

4. Lee, P.M., M. Priest, M.S. Stark, J.J. Wilkinson, J.R. Lindsay-Smith, R.I. Taylor, and S. Chung, Extraction and tribological investigation of top ring zone oil from a gasoline engine. Proceedings of the Institution of Mechanical Engineers, Part J: Journal of Engineering Tribology, 2006. 220(3): p. 171-180.

5. Hsu, S.M., C.S. Ku, and P.T. Pei, Oxidative Degradation Mechanisms of Lubricants, in Aspects of Lubricant Oxidation. ASTM STP 916, W.H. Stadmiller and A.N. Smith, Editors. 1986, American Society for Testing and Materials: Philadelphia. p. 27-48.

6. Kumar, S., N.M. Mishra, and P.S. Mukherjee, Additives depletion and engine oil condition - a case study. Industrial Lubrication and Tribology, 2005. 57(2): p. 69-72.

7. Herbeaux, J.-L. and W.E. VanArsdale. Mechanical Degradation of Multi-Grade Engine Oils. in International Congress and Exposition. 1993. Detroit, Michigan: SAE paper 930690.

8. Yasutomi, S., Y. Maeda, and T. Maeda, Kinetic Approach to Engine Oil .3. Increase in Viscosity of Diesel-Engine Oil Caused By Soot Contamination. Industrial \& Engineering Chemistry Product Research and Development, 1981. 20(3): p. 540-544.

9. Arcoumanis, C., M. Duszynski, H. Lindenkamp, and H. Preston, Measurement of Lubricating Film Thickness in the Cylinder of a Firing Engine Using LIF. SAE Paper 982435, 1998.

10. Inagaki, H., A. Saito, M. Murakami, and T. Konomi, Measurement of Oil Film Thickness Distribution on Piston Surface Using the Fluorescence Method (Development of measuring System). JSME International Journal (Series B), 1997. 40(3): p. 487-493.

11. Nakayama, K., I. Morio, T. Katagiri, and Y. Okamoto. A Study for Measurement of Oil Film Thickness on Engine Bearing by using Laser Induced Fluorescence (LIF) Method. in 2003 SAE World Congress. 2003. Detroit, Michigan: SAE 2003-01-0243.

12. Taylor, R.I. and P.G. Evans, In-situ Piston Measurements. Proceedings of the Institution of Mechanical Engineers, Part J: Journal of Engineering Tribology, 2004. 218(3): p. 185-200.

13. Courtney-Pratt, J.S. and G.K. Tudor, An Analysis of the Lubrication between the Piston Rings and Cylinder Wall of a Running Engine. Proceedings of the Institution of Mechanical Engineers, 1946. 155: p. 293.

14. Dow, T.A., C.A. Schiele, and R.D. Stockwell, Technique for Experimental Evaluation of Piston Ring-Cylinder Film Thickness. Journal of Lubrication Technology, 1983. 105: p. 353.

15. Furuhama, S. and T. Sumi, A Dynamic Theory of Piston-RIng Lubrication (3rd Report, Measurement of Oil FIlm Thickness). Bulletin of JSME, 1961. 4(16): p. 744.

16. Sherrington, I. and E.H. Smith, Experimental methods for measuring the oil-film thickness between the piston-rings and cylinder-wall of internal combustion engines. Tribology International, 1985. 18(6): p. 315-320.

17. Hamilton, G.M. and S.L. Moore, First Paper: Measurement of the Oil-Film Thickness between the Piston Rings and Liner of a Small Diesel Engine. Proceedings of the Institution of Mechanical Engineers, 1974a. 188(1): p. 253-261.

18. Hamilton, G.M. and S.L. Moore, Second Paper: Comparison Between Measured and Calculated Thicknesses of the Oil-film Lubricating Piston Rings. Proceedings of the Institution of Mechanical Engineers, 1974b. 188(20).

19. Moore, S.L., Measurement of the Ring to Liner Oil Film Thickness in a Caterpillar 1-G Diesel Engine. SAE Paper 790730, 1979.

20. Moore, S.L., Piston Ring Oil Film Thickness - The Effect of Viscosity. 1985, SAE Paper 850439.

21. Moore, S.L., Piston ring lubrication in a two-stroke diesel engine. Wear, 1981. 72(3): p. 353369. 
22. Moore, S.L. and G.M. Hamilton, The Starved Lubrication of Piston Rings in a Diesel Engine Journal Mechanical Engineering Science, 1978. 20: p. 345-352.

23. Shin, K., Y. Tateishi, and S. Furuhama, Measurement of oil-film-thickness between piston ring and cylinder. SAE Paper 830068, 1983.

24. Söchting, S.J. and I. Sherrington, The effect of load and viscosity on the minimum operating oil film thickness of piston-rings in internal combustion engines. Proceedings of the Institution of Mechanical Engineers, Part J: Journal of Engineering Tribology, 2009. 223(3): p. 383-391.

25. Tamminen, J., C.-E. Sandström, and P. Andersson, Influence of load on the tribological conditions in piston ring and cylinder liner contacts in a medium-speed diesel engine. Tribology International, 2006. 39(12): p. 1643-1652.

26. Takiguchi, M., R. Sasaki, I. Takahashi, F. Ishibashi, S. Furuhama, R. Kai, and M. Sato, Oil film thickness measurement and analysis of a three ring pack in an operating diesel engine. SAE paper 2000-01-1787, 2000.

27. Garcia-Atance Fatjo, G., E.H. Smith, and I. Sherrington, Mapping lubricating film thickness, film extent and ring twist for the compression-ring in a firing internal combustion engine. Tribology International, 2013. 70(0): p. 112-118.

28. Ting, L.L., Development of a Laser Fluorescence Technique For Measuring Piston Ring Oil Film Thickness. Journal of Lubrication Technology, 1980. 102(2): p. 165-170.

29. Hoult, D.P., J.P. Lux, V.W. Wong, and S.A. Billian, Calibration of Laser Fluorescence Measurements of Lubricant Film Thickness in Engines. SAE Paper 881587, 1988.

30. Dearlove, J. and W.K. Cheng, Simultaneous Piston Ring Friction and Oil Film Thickness Measurements in a Reciprocating Test Rig. SAE Paper 952470, 1995.

31. Sanda, S., M. Murakami, T. Noda, and T. Konomi, Analysis of Lubrication of a Piston Ring Package (Effect of oil starvation on oil film thickness). JSME International Journal Series B, 1997. 40(3): p. 478-486.

32. Arcoumanis, C., M. Duszynski, E. Pyke, and H. Preston, Cold-start Measurement of the Lubricating Film Thickness in the Cylinder of a Firing Diesel Engine. SAE Paper 982436, 1998.

33. Seki, T., K. Nakayama, T. Yamanda, A. Yoshida, and M. Takiguchi, A study on variation in oil film thickness of a piston ring package: variation of oil film thickness in piston sliding direction. JSAE Review, 2000. 21(3): p. 315-320.

34. Takiguchi, M., K. Nakayama, S. Furuhama, and H. Yoshida, Variation of Piston Ring Oil Film Thickness in an Internal Combustion Engine - Comparison Between Thrust and Anti-Thrust Sides. SAE Paper 980563, 1998.

35. Yilmaz, E., T. Tian, V.W. Wong, and J.B. Heywood. The Contribution of Different Oil Consumption Sources to Total Oil Consumption in a Spark Ignition Engine. in Powertrain and Fluid Systems Conference and Exhibition. 2004. Meeting Location:Tampa, Florida, USA: SAE 2004-01-2909.

36. Casey, S.M., Analysis of Lubricant Film Thickness and Distribution along the Piston/Ring/Liner Interface in a Reciprocating Engine. Master Degree, in Department of Mechanical Engineering. 1998, Massachusetts Institute of Technology.

37. Brown, M.A., H. McCann, and D.M. Thompson, Characterization of the Oil Film Behaviour Between the Liner and Piston of a Heavy-Duty Diesel Engine. SAE Paper 932784, 1993.

38. Baba, Y., H. Suzuki, Y. Sakai, D.L.T. Wei, T. Ishima, and T. Obokata. PIV/LIF Measurements of Oil Film Behavior on the Piston in I. C. Engine. in 8th International Conference on Engines for Automobile. 2007. Capri, Naples, Italy: SAE Paper 2007-24-0001.

39. Thirouard, B. and T. Tian. Oil Transport in the Piston Ring Pack (Part 1): Identification and Characterization of the Main Oil Transport Routes and Mechanisms. in 2003 JSAE/SAE International Spring Fuels and Lubricants Meeting. 2003. Yokohama, Japan: SAE International Paper 2003-01-1952.

40. Nakayama, K., T. Seki, M. Takiguchi, T. Someya, and S. Furuhama, The Effect of Oil Ring Geometry on Oil Film Thickness in the Circumferential Direction of the Cylinder. 1998. SAE Paper 982578. 
41. Thirouard, B., T. Tian, and D.P. Hart, Investigation of oil transport mechanisms in the piston ring pack of a single-cylinder diesel engine, using two-dimensional, laser-induced fluorescence. SAE Paper 982658, 1998.

42. Dwyer-Joyce, R.S., D.A. Green, P. Harper, R. Lewis, S. Balakrishnan, P.D. King, H. Rahnejat, and S. Howell-Smith. The Measurement Of Liner-Piston Skirt Oil Film Thickness By An Ultrasonic Means. in SAE 2006 World Congress. 2006. Warrendale, Pennsylvania, USA: SAE 2006-01-0648.

43. Mills, R., E. Avan, and R. Dwyer-Joyce, Piezoelectric sensors to monitor lubricant film thickness at piston-cylinder contacts in a fired engine. Proceedings of the Institution of Mechanical Engineers, Part J: Journal of Engineering Tribology, 2013. 227(2): p. 100-111.

44. Gasni, D., M.K. Wan Ibrahim, and R.S. Dwyer-Joyce, Measurements of lubricant film thickness in the iso-viscous elastohydrodynamic regime. Tribology International, 2011. 44(7-8): p. 933944.

45. Avan, E.Y., R. Mills, and R. Dwyer-Joyce, Ultrasonic Imaging of the Piston Ring Oil Film During Operation in a Motored Engine - Towards Oil Film Thickness Measurement. SAE Paper 2010-01-2179, 2010.

46. Harper, P., R.S. Dwyer-Joyce, U. Sjodin, and U. Olofsson, Evaluation of an ultrasonic method for measurement of oil film thickness in a hydraulic motor piston ring. Tribology and Interface Engineering Series, 2005. 48: p. 305-312.

47. Zhang, J., B.W. Drinkwater, and R.S. Dwyer-Joyce, Calibration of the ultrasonic lubricantfilm thickness measurement technique. Measurement and Science Technology, 2005. 16(9): p. 1784-1791.

48. Avan, E.Y., A. Spencer, R.S. Dwyer-Joyce, A. Almqvist, and R. Larsson, Experimental and numerical investigations of oil film formation and friction in a piston ring-liner contact. Proceedings of the Institution of Mechanical Engineers, Part J: Journal of Engineering Tribology, 2013. 227(2): p. 126-140.

49. Sherrington, I., Oil film thickness measurement: a contribution to the understanding and control of lubrication in the piston-ring packs of IC engines. Proceedings of the Institution of Mechanical Engineers, Part J: Journal of Engineering Tribology, 2011. 225(7): p. 595-601.

50. Radcliffe, C.D., An Experimental and Analytical Study of a Piston Ring Pack. PhD Thesis, in Department of Mechanical Engineering. 1993, University of Leeds: Leeds.

51. Brown, S.R. and G.M. Hamilton, Negative Pressures Under a Lubricated Piston Ring. Journal Mechanical Engineering Science, 1978. 20(1): p. 49-57.

52. Dhar, A., A.K. Agarwal, and V. Saxena, Measurement of dynamic lubricating oil film thickness between piston ring and liner in a motored engine. Sensors and Actuators A: Physical, 2009. 149(1): p. 7-15.

53. Mills, R., E. Avan, and R. Dwyer-Joyce, Piezoelectric sensors to monitor lubricant film thickness at piston-cylinder contacts in a fired engine. Proceedings of the Institution of Mechanical Engineers, Part J: Journal of Engineering Tribology, 2013. 227(2): p. 100-111.

54. Mufti, R.A. and M. Priest, Experimental evaluation of piston assembly friction under motored and fired conditions in a gasoline engine. Journal of Tribology, 2005. 127: p. 826-836.

55. Mufti, R.A. and M. Priest, Effect of Engine Operating Conditions and Lubricant Rheology on the Distribution of Losses in an Internal Combustion Engine. Journal of Tribology, 2009. 131.

56. Mufti, R.A., M. Priest, and R.J. Chittenden, Analysis of piston assembly friction using the indicated mean effective pressure experimental method to validate mathematical models. Proceedings of the Institution of Mechanical Engineers, Part D, 2006. 222.

57. Stark, M.S., J.J. Wilkinson, P.M. Lee, J.R. LindsaySmith, M. Priest, R.I. Taylor, and S. Chung. The Degradation of Lubricants in Gasoline Engines: Lubricant Flow and Degradation in the Piston Assembly. in 31st Leeds-Lyon. Life Cycle Tribology. 2004. Leeds, UK: Elsevier.

58. Hammond, C., A Mechanistic Study of the Autoxidation of Ketones in the Liquid Phase, in Department Chemistry. 2003, PhD Thesis. University of York York.

59. ASTM, ASTM D4683 - 10 Standard Test Method for Measuring Viscosity of New and Used Engine Oils at High Shear Rate and High Temperature by Tapered Bearing Simulator Viscometer at $150{ }^{\circ} \mathrm{C}$. D4683-10. 
60. Seki, T., Nakayama, T., Yamanda, A., Yoshida, and Takiguchi, M, A study on variation in oil film thickness of a piston ring package: variation of oil film thickness in piston sliding direction. JSAE Review, 2000, 21(3): p. 315-320 